\title{
Hypertrophic Cranial Pachymeningitis Associated with Mixed Connective Tissue Disease; A Comparison with Idiopathic and Infectious Pachymeningitis
}

\author{
Mika Fujimoto, Jun-ichi Kira, Hiroyuki Murai, Takeo Yoshimura, \\ Katsumi TAKIZAwa and Ikuo Goto
}

\begin{abstract}
This is the first report describing hypertrophic cranial pachymeningitis which developed in association with mixed connective tissue disease (MCTD). A 56-year-old man with a two-year history of MCTD gradually developed symptoms of headache and blurred vision. Bilateral papilledema and increased opening pressure and mild pleocytosis of the cerebrospinal fluid were noted. Magnetic resonance imaging of the brain revealed a diffuse thickening and a gadoliniumenhancement of the cranial dura mater. While five previous patients, diagnosed as idiopathic or infectious hypertrophic cranial pachymeningitis in our department, had either otitis media or sinusitis and showed multiple cranial nerve involvement, the present patient had neither otitis media nor sinusitis and did not show any cranial nerve involvement other than papilledema.
\end{abstract}

(Internal Medicine 32: 510-512, 1993)

Key words: MRI, thickening of dura mater, papilledema

\section{Introduction}

Hypertrophic cranial pachymeningitis is a chronic progressive inflammation of the cranial dura mater. In most cases, the etiology is unspecified. But several cases have been reported, which were caused by either fungal infections or bacterial infections (1-5) or were associated with autoimmune diseases (6-8). To our knowledge, this is the first report of hypertrophic cranial pachymeningitis associated with a mixed connective tissue disease (MCTD).

\section{Case Report}

A 56-year-old man developed pain in bilateral elbow and knee joints, a low grade fever, Raynaud phenomenon and a malar rash in May 1985. Antinuclear antibodies (ANA) and anti-RNP antibodies were strongly positive, but an LE-test was negative. MCTD was diagnosed and administration of corticosteroids alleviated his symptoms. In January 1991, a frontal headache developed and persisted with some fluctuations. Nine months later, he gradually developed blurred vision bilaterally. On admission to our hospital, a general physical examination revealed malar rash, limitation of the elbow joint motility and crepitant rales on the bilateral lower chest. Neuro- logically, he had decreased visual acuity and papilledema bilaterally.

Complete blood counts, blood chemistry and urinalysis were all normal. The erythrocyte sedimentation rate (ESR) was 31 $\mathrm{mm} / \mathrm{hr}$ and CRP was $4.8 \mathrm{mg} / \mathrm{dl}$. ANA was detected at 1:160 (speckled type) and anti-RNP antibody was positive at 1:1,600 in sera, but other autoantibodies and LE-test were negative. A lumbar puncture yielded a clear, colorless cerebrospinal fluid (CSF) with an opening pressure of $290 \mathrm{mmH}_{2} \mathrm{O}$. CSF showed 12 mononuclear cells $/ \mathrm{mm}^{3}$, protein level of $98 \mathrm{mg} / \mathrm{dl}$ and glucose $61 \mathrm{mg} / \mathrm{dl}$. A culture of CSF and anti-viral antibodies in CSF were both negative. Strand shadows were noted in the bilateral lower lung fields on the chest X-ray. A respiratory function test showed a restrictive pattern (\%VC was $67 \%$ and $\mathrm{FEV}_{1.0 \%} 83 \%$ ). Magnetic resonance imaging (MRI) of the brain showed a diffuse thickening and marked gadolinium enhancement of the dura mater in the cranial convexity, skull base and posterior fossa (Fig. 1). Gallium scintigraphy revealed an abnormal accumulation in the left temporal convexity and bilateral lower lung fields.

Hypertrophic cranial pachymeningitis was diagnosed. Oral prednisolone and intravenous concentrated glycerin alleviated his symptoms and CSF pleocytosis (Fig. 2). However, MRI of the brain three months after the first scan showed practically no

From the Department of Neurology, Neurological Institute, Faculty of Medicine, Kyushu University, Fukuoka

Received for publication April 1, 1992; Accepted for publication May 26, 1993

Reprint requests should be addressed to Dr. Jun-ichi Kira, the Department of Neurology, Neurological Institute, Faculty of Medicine, Kyushu University, Maidashi 3-1-1, Fukuoka 812, Japan 

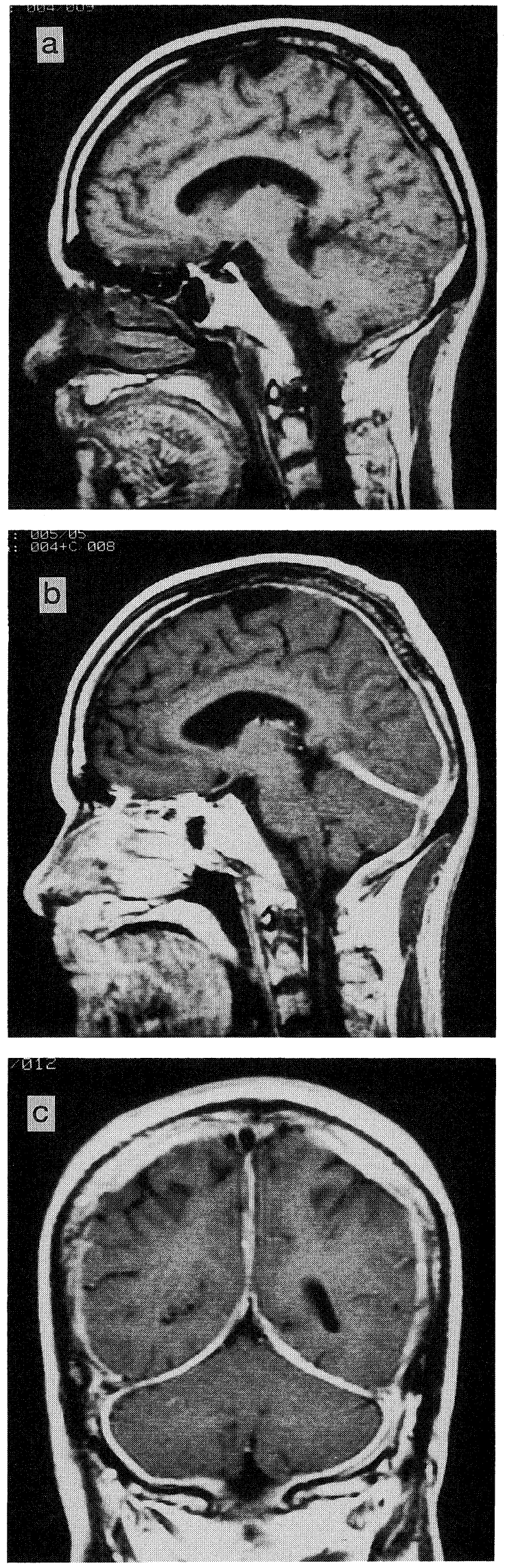

changes. Although azathioprine was added during the tapering period of prednisolone, both the headache and blurred vision recurred.

\section{Discussion}

The present patient met the current diagnostic criteria of MCTD (9). A diffuse thickening and marked gadolinium enhancement of the cranial dura mater shown by brain MRI, abnormal accumulation in the left temporal convexity on gallium scintigraphy and mild CSF pleocytosis strongly suggested hypertrophic cranial pachymeningitis. A diagnosis of hypertrophic cranial pachymeningitis in living patients has been difficult. However, recently reports of hypertrophic cranial pachymeningitis have increased in which MRI is used to help determine the diagnosis (10).

Several etiologies of hypertrophic cranial pachymeningitis have been reported, such as syphilis $(1,2)$, tuberculosis $(3)$, fungus $(4,5)$, rheumatoid arthritis $(6,7)$, Wegener's granulomatosis (8), otolaryngological disease (11), and injury (12). In the present patient, we found no specific cause except for MCTD. Although hypertrophic cranial pachymeningitis has never been reported in MCTD, MCTD is well known to have several neurologic complications, such as aseptic meningitis, transverse myelitis, trigeminal neuritis and cerebellar dysfunction (13). Most of these are thought to be associated with an inflammatory process of MCTD.

Therefore, we compared the clinical features of the present patient with those of five other patients who were diagnosed as idiopathic or infectious hypertrophic cranial pachymeningitis in our department (Table 1). The following differences were noted. 1) Otitis media or sinusitis was present in the five other patients, but not in the present patient. 2) Multiple cranial nerve involvement was seen in the five other patients, but the present patient showed no cranial nerve involvement other than papilledema. 3) Although oral prednisolone alleviated the clinical symptoms in all administered patients, the symptoms recurred more easily when tapering the drug in the present patient than in the other patients. Together with the frequent occurrence of neurologic complications in MCTD, these differences may suggest the unique association between hypertrophic cranial pachymeningitis and MCTD. We therefore propose that the relationship between autoimmune diseases and hypertrophic cranial pachymeningitis should be carefully noted and that MRI examination increases the possibility of finding similar cases.

\section{References}

1) Kuramochi $S$, Hosoda $Y$, Matsuyama $H$, Shinohara $Y$. Thromboendophlebitis obliterans of dural sinuses associated with

Fig. 1. Sagittal T1-weighted MR image of the brain (TR400/TE20) shows a diffuse thickening of the dura mater in the cranial convexity and posterior fossa (a). Sagittal and coronal T1-weighted gadolinium-enhanced MR images (TR600/TE20) shows a diffuse enhancement of the dura mater (b, c). 


\section{FüImoto et al}

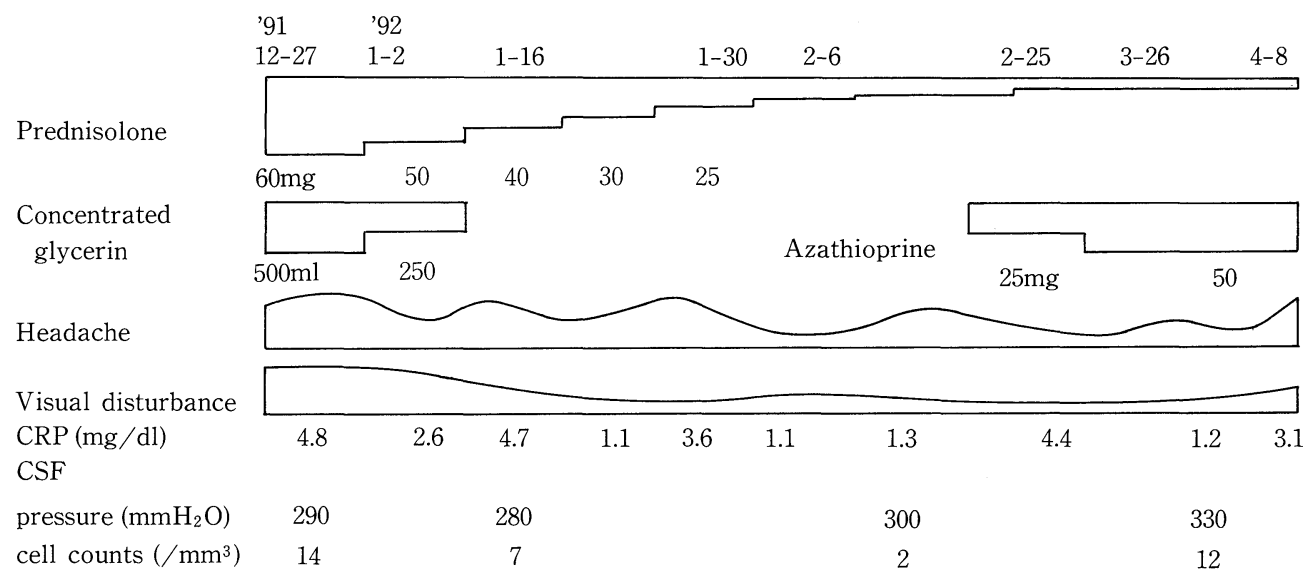

Fig. 2. The clinical course of the present patient. After a gradual tapering of prednisolone, headache and blurred vision recurred and CSF again showed a mild pleocytosis. CSF pressure remained practically unchanged, regardless of the type of treatment.

Table 1. The Clinicoradiological Features of Six Cases of Hypertrophic Cranial Pachymeningitis

\begin{tabular}{|c|c|c|c|c|c|c|}
\hline Case & 1 & 2 & 3 & 4 & 5 & $\begin{array}{l}6 \text { (present } \\
\text { case) }\end{array}$ \\
\hline Age, Sex & $59 \mathrm{~F}$ & $54 \mathrm{M}$ & $70 \mathrm{~F}$ & $63 \mathrm{M}$ & $36 \mathrm{M}$ & $56 \mathrm{M}$ \\
\hline $\begin{array}{l}\text { Cranial nerve } \\
\text { involvement }\end{array}$ & + & + & + & + & + & - \\
\hline $\begin{array}{c}\text { Otitis } \\
\text { media/sinusitis }\end{array}$ & + & + & + & + & + & - \\
\hline Etiology & Aspergillosis & idiopathic & idiopathic & idiopathic & idiopathic & MCTD \\
\hline Therapy & $\begin{array}{l}\text { Anti-fungal } \\
\text { drug }\end{array}$ & $\begin{array}{l}\text { cortico- } \\
\text { steroid }\end{array}$ & $\begin{array}{l}\text { cortico- } \\
\text { steroid }\end{array}$ & - & $\begin{array}{l}\text { cortico- } \\
\text { steroid }\end{array}$ & $\begin{array}{l}\text { cortico- } \\
\text { steroid }\end{array}$ \\
\hline $\begin{array}{c}\text { Efficacy of therapy } \\
\text { Clinical }\end{array}$ & + & + & + & ND & + & \pm \\
\hline $\mathrm{CT} / \mathrm{MRI} / \mathrm{Ga}$ scinti & + & ND & + & ND & + & - \\
\hline
\end{tabular}

ND: not determined.

hypertrophic pachymeningitis. Vasc Surg 13: 104, 1979.

2) Moore AP, Rolfe EB, Jones EL. Pachymeningitis cranialis hypertrophica. J Neurol Neurosurg Psychiatry 48: 942, 1985.

3) Callebaut J, Dormont D, Dubois B, Chiras J, Bories J. Contrast-enhanced MR imaging of tuberculous pachymeningitis cranialis hypertrophica: case report. Am J Neuroradiology 11: 821, 1990.

4) Gorell JM, Palutke WA, Chason JL. Candida pachyminingitis with multiple cranial nerve pareses. Arch Neurol 36: 719, 1979.

5) Murai H, Kira J, Kobayashi T, Goto I, Inoue H, Hasuo K. Hypertrophic cranial pachymeningitis due to Aspergillus flavus. Clin Neurol Neurosurg 94: 247, 1992.

6) Yuh WTC, Drew JM, Rizzo M, Ryals TJ, Yutaka S, Bell WE. Evaluation of pachymeningitis by contrast-enhanced MR imaging in a patient with rheumatoid disease. Am J Neuroradiology 11: 1247, 1990.

7) Markenson JA, McDougal JS, Tsairis P, Lockshin MD, Christian CL. Rheumatoid meningitis. A localized immune process. Ann Intern Med 90: 786, 1979.

8) Eto F, Shimada Y, Endo H, Mozai T. An autopsied case of Wegener's granulomatosis with remarkable pachymeningitis. Rinsho Shinkeigaku 16: $326,1976$.

9) Sharp GC, Irvin WS, Tan EM, Gould RG, Holman HR. Mixed connective tissue disease - An apparently distinct rheumatic disease syndrome associated with a specific antibody to an extractable nuclear antigen (ENA). Am J Med 52: 148, 1972.

10) Martin N, Masson C, Henin D, Mompoint D, Marsault C, Nahum H. Hypertrophic cranial pachymeningitis. Am J Neuroradiology 10: 477, 1989.

11) Ishii $A$, Ohkoshi $N$, Nagata $H$, Mizusawa $H$, Kanazawa I. A case of Garcin's syndrome caused by pachymeningitis secondary to otitis media, responsive to antibiotic therapy. Rinsho Shinkeigaku 31: 837, 1991.

12) Naffziger HC, Stem WE. Chronic pachymeningitis. Report of a case and review of the literature. Arch Neurol Psychiatry 62: 383, 1949.

13) Lazard MA, Cocco JAM, Cataggio LJ, Babini SM, Messina OD, Marteo OG. Clinical and serologic characteristics of patients with overlap syndrome: Is mixed connective tissue disease a distinct clinical entity? Medicine 68: 58, 1989. 